\title{
O CASO DAS FÁBRICAS DE CELULOSE NO RIO URUGUAI: ANÁLISE SOB O PRISMA DO DIREITO AMBIENTAL INTERNACIONAL
}

\section{THE CASE OF PULP FACTORIES IN URUGUAY RIVER: THE ANALYSIS FROM INTERNATIONAL ENVIRONMENTAL LAW}

\author{
${ }^{1}$ Rogerio Portanova \\ ${ }^{2}$ Thaís Dalla Corte
}

\section{RESUMO}

Perante um contexto de desastres e de danos ecológicos, decorrentes do desenvolvimento industrial, surge, no século XX, o Direito Ambiental Internacional (DAI). Há uma linha histórica de acontecimentos que influenciaram a sua sistematização, especialmente as Conferências sobre Meio Ambiente (com realce para Estocolmo (1972)). Assim, o DAI configura-se como um conjunto de normas (de soft e de hard law) que dão suporte às decisões das controvérsias levadas ao conhecimento dos tribunais internacionais. Esse é o caso das fábricas de celulose no Rio Uruguai (2006-2010), em cuja decisão discutiu-se, entre os princípios e regras do DAI, o Estudo de Impacto Ambiental (EIA), o desenvolvimento sustentável, o equilíbrio ecológico, a prevenção, a precaução etc. Contudo, mesmo diante deles, o acórdão da Corte não condenou o Uruguai pelo descumprimento de obrigações substanciais, deixando de avançar, em sua atuação, a favor do meio ambiente. Diante do exposto, a presente pesquisa, através do método de abordagem indutivo, objetiva analisar, com base no Direito Ambiental Internacional, o caso das fábricas de celulose no Rio Uruguai.

Palavras-chave: Direito ambiental internacional, Fábricas de celulose, Princípios, Regras

\begin{abstract}
Against a backdrop of disasters and ecological damage arising from industrial development, arises in the XX century, the International Environmental Law. There is a historical line of events that influenced their systematization, especially the Conferences on Environment (with emphasis on Stockholm (1972)). Thus, the International Environmental Law is configured as a set of rules (soft and hard law) that support the decisions of disputes brought to the attention of the international tribunals. This is the case of Pulp Mills on the Uruguay River (20062010), in whose decision is discussed, among other principles and International Environmental Law rules, the Environmental Impact Assessment, sustainable development, ecological balance, prevention, precaution etc. However, despite these discussions, the judgment of the Court did not condemn Uruguay for the breach of substantial obligations, failing to advance in its activities in favor of the environment. In this sense, this research, through the inductive method, analyzes, based on international environmental law, the case of the Pulp Mills on the Uruguay River.
\end{abstract}

\footnotetext{
${ }^{1}$ Pós-Doutorado pela Universidade Lusíada de Lisboa - ULUSIADA, Lisboa, Portugal. Presidente da Fundação de Amparo à Pesquisa do Estado de Santa Catarina, FAPESC, Santa Catarina, (Brasil). E-mail: rogerio.portanova@ufsc.br.

${ }^{2}$ Doutoranda em andamento em Direito na Universidade Federal de Santa Catarina - UFSC, Santa Catarina, Brasil. Advogada no escritório Dalla Corte Advocacia, DC ADVOCACIA, (Brasil). E-mail: tha_dallacorte@ hotmail.com.
} 
Keywords: International environmental law, Pulp mills, Principles, Rules 


\section{INTRODUÇÃO}

O litígio das papeleras, Argentina versus Uruguai, julgado pela Corte Internacional de Justiça (CIJ), em abril de 2010, é um dos casos paradigmáticos do Direito Ambiental Internacional (DAI). Ele açambarcou, em sua discussão, diversos temas ambientais, sendo, um dos principais, o Estudo de Impacto Ambiental (EIA). Contudo, o DAI possuiu nele uma aplicação aquém do que se esperava em relação à proteção do meio ambiente. Analisando a sua formatação histórica, desde os seus antecedentes até o seu surgimento em 1970 (tendo como marco a Conferência de Estocolmo (1972)), verifica-se que certas questões - como o caráter, muitas vezes, irreversível dos danos ao meio, a equidade intergeracional, o bem-estar dos povos, entre outras - já sedimentadas na discussão ambiental internacional, não foram, infelizmente, consideradas pela decisão (especialmente no que se refere às obrigações substanciais) prolatada pela CIJ. O julgamento, o qual perpassou pela investigação de obrigações processuais e materiais do caso, contou com votos importantes, como o do juiz Antônio Augusto Cançado Trindade (fazendo-se mister destacar, na opinião separa elaborada por ele, sua argumentação relacionada ao princípio da precaução). Contudo, mesmo diante de relevantes fundamentos, não houve a condenação do Uruguai por violações materiais.

O que se evidencia, também, é que as promessas de crescimento econômico (mascaradas sob o discurso de desenvolvimento sustentável) - como as relacionadas a aumento de empregos e, consequentemente, de renda - fizeram com que parcela da população aceitasse sem oposições, inicialmente, a autorização concedida pelo governo às empresas estrangeiras (de nacionalidades espanhola e finlandesa) para a implementação de duas fábricas de celulose no Rio Uruguai (em território uruguaio), desconsiderando os graves danos ambientais que a instalação e a operacionalização delas acarretariam à região (de forma local e transfronteiriça). Posteriormente, com a disseminação de informações sobre os malefícios que as fábricas de celuloses acarretariam ao ambiente, especialmente, ao solo, às florestas e aos cursos de água (em nível de bacia hidrográfica), o caso passou a contar com um considerável engajamento da sociedade civil, sendo este ponto, inclusive, um marco dele. Assim, Pulp Mills, antes de se tornar, em maio de 2006, um conflito entre Estados, foi levado ao conhecimento da Comissão de Administração do Rio Uruguai (CARU), no final de 2001, por uma ONG argentina. Ainda, após judicializado, em sucessivas fases do processo, ONGs e outras entidades da sociedade civil, de ambos os países, participaram das avaliações de impacto e das ações relacionadas ao monitoramento ambiental. 
Convém mencionar que essa pressão social surtiu efeitos, já que uma das companhias (a espanhola ENCE) autorizada a construir uma das fábricas (Celulosa M'Bopicuá (CMD)) desistiu da sua construção em setembro de 2006, enquanto a outra empresa (a finlandesa ABBOTNIA) conclui as obras e passou a operacionalizar a fábrica, chamada de Orion, em setembro de 2007. Nesse contexto, esta pesquisa, no ramo das Ciências Jurídicas e Sociais, insere-se, principalmente, nas áreas do Direito Internacional, do Direito Ambiental Internacional e do Direito Ambiental. Assim, a partir do método de abordagem indutivo, este estudo possui os seguintes problemas para verificação: quais as regras e os princípios do Direito Ambiental Internacional foram aplicados no caso das fábricas de celulose no Rio Uruguai? Primou a sua decisão pela proteção do meio ambiente? Nesse sentido, objetiva-se analisar, com base no Direito Ambiental Internacional, a controvérsia de Pulp Mills entre Argentina e Uruguai. É o que se passa, detalhadamente, a explorar.

\section{O CONTEXTO HISTÓRICO DA FORMAÇÃO DO DIREITO AMBIENTAL INTERNACIONAL (DAI) COM ENFOQUE NAS PRINCIPAIS CONFERÊNCIAS SOBRE MEIO AMBIENTE}

O Direito Ambiental Internacional (DAI) ${ }^{1}$ é um dos ramos (subsistema) do Direito Internacional, possuindo escopos, principiologia e forma de administração específicos. Nesse sentido, é incorreto compreendê-lo como uma extensão do Direito Ambiental, já que é em âmbito internacional que se encontra a gênese das normas internas sobre meio ambiente (essa relação de "cima para baixo", sobre a qual se verifica, ainda, certa resistência de parte da doutrina ambiental brasileira em reconhecê-la, fica muito evidente ao se analisar a Lei n. ${ }^{\circ}$ 6.938/81 (marco inicial do Direito Ambiental nacional) e o artigo 225, da CF/88 (dispositivo constitucional cerne do Direito Ambiental nacional)). Perante esse contexto, faz-se importante, inicialmente, analisar a formatação histórica do Direito Ambiental Internacional, identificando como ele influencia os Estados na elaboração de suas normas internas.

Antes da sistematização do DAI - a qual surgiu em Estocolmo (1972) e se solidificou com a realização da Rio 92 - encontrava-se, em matéria ambiental internacional, apenas, a

\footnotetext{
${ }^{1}$ Entende-se que a designação Direito Ambiental Internacional, a partir do estudo de sua formatação, é mais adequada do que a já consagrada nominação de Direito Internacional Ambiental.
} 
existência de normas referentes a determinados elementos ambientais, as quais, apesar de importantes, por si só, não o formatavam, propriamente, como um ramo autônomo. Em outras palavras, pode-se dizer que o meio ambiente, enquanto macrobem, ainda não era uma

preocupação internacional relevante. Até então, tutelava-se, basicamente, os bens comuns (como a água, o ar, entre outros), pois, por serem tranfronteiriços, eram utilizados indiscriminadamente por todos, o que causava um desequilíbrio na balança de poderes, gerando situações que demandavam, então, por regulamentação.

É a partir de 1945, após importantes acontecimentos internacionais, que se expande a discussão internacionalista para além de questões clássicas, como soberania, comércio e paz entre os Estados. O caso da Fundição Trail (Trail Smelter Case) - referente à queixa apresentada pelo governo dos Estados Unidos (cujo território foi afetado por poluentes industriais (dióxido de enxofre)) contra o Canadá (responsável pela emissão deles, por intermédio de empresa que trabalhava com chumbo e zinco) à Comissão Mista Internacional foi finalizado, após muitos anos de discussão, via arbitragem, em 1941, passando, de forma inaugural e histórica, a incorporar o meio ambiente entre os objetos de tutela internacional. Esse episódio foi o responsável por reconhecer a responsabilidade internacional dos Estados na prevenção de danos ambientais trasnfronteiriços.

Assim, no cenário pré-Estocolmo (1972), como antecedentes e incentivadores à formatação do Direito Ambiental Internacional (DAI), encontram-se algumas fontes de direito internacional que tinham por objeto elementos ambientais e, também, verifica-se o surgimento de organizações internacionais dedicadas à conservação e recuperação dos recursos naturais (sendo importante destacar, entre estas, a International Union for Conservation of Nature (IUCN) fundada em 1948 e a World Wide Fund for Nature (WWF) constituída em 1961, ambas com sede na Suíça).

Nessa senda, ressalta-se que a elaboração de normas ambientais internacionais e a criação de Organizações atuantes, de forma global, em causas ambientais foram impulsionadas, até mesmo, por desastres ecológicos cada vez mais recorrentes a partir do século XX, os quais passaram a demonstrar que a intervenção humana desregulada no meio e que o crescimento econômico sob os fundamentos liberais possuíam grande potencial destruidor coletivo.

Para ilustrar essa afirmação, pode-se citar o caso de Minamata (Japão) ocorrido em 
1956, o qual é paradigmático. A partir dele, verificou-se que a morte (já que uma das grandes preocupações do Direito é a tutela da vida) não era produto, apenas, da guerra, mas que ela era consequência da própria paz da sociedade industrial, a qual despejava mercúrio, há anos, no mar de onde a população retirava recursos (em especial, peixes e crustáceos) para sua subsistência. O resultado foi um envenenamento em massa dos cidadãos e até óbitos (em torno de setecentos), num trágico acontecimento que ganhou repercussão internacional e gerou diversos protestos. Além disso, vale mencionar que a água contaminada alastrou-se para outras regiões da baía de Minamata localizada na ilha de Kyushu (JP). Toda essa situação ocasionou discussões internacionais em matéria ambiental.

Diante dessa conjuntara, a partir de 1959, foram elaboradas convenções, com intuito regulamentário e protetivo, sobre alguns elementos comuns do meio ambiente, como a pesca. Mais tarde, ainda, outros recursos foram englobados nessa lógica, como o espaço, o mar, a Antártida etc. Já, em 1960, o enfoque normativo centrou-se na energia nuclear. Por sua vez, em 1961, a tutela jurídica focou-se na proteção de cultivares e de algumas espécies; entre outros exemplos. (BIRNIE; BOYLE, 2002, p. 76-79).

Ainda, nessa época (anos 60), impulsionando o movimento ambientalista internacional, por chamar a atenção da sociedade e, em especial, da comunidade científica internacional para o tema, necessita-se destacar, como mais um dos precedentes que fomentou a emergência do Direito Ambiental Internacional (DAI), o livro intitulado Silent Spring (Primavera Silenciosa), escrito pela bióloga norte-americana Rachel Carson publicado em 1962. Nele, ela criticou a confiabilidade desmedida da civilização no progresso tecnológico, denunciou a desinformação propagada pelas indústrias de químicos e documentou o uso indiscriminado de pesticida $\left(\mathrm{DDT}^{2}\right)$ pelo homem no ambiente. Através da obra, a autora apresentou os efeitos prejudiciais (de forma geral, intoxicações e contaminações) que a utilização e o contato com inseticidas podem acarretar à saúde humana, bem como ao meio ambiente. Nesse sentido, alertou para o fato de que o desenvolvimento, na verdade, representava degradação. Dessa forma, identificou que, caso não ocorresse um controle nessa relação, a estação primaveril poderia acabar, diante da ameaça a que todos os seus componentes se encontravam submetidos. (CARSON, 1969, p. 12-22).

Outra referência importante para o Direito Ambiental Internacional nesse período foi o Clube de Roma (1968), o qual, constituído por várias personalidades de renome, ${ }^{3}$ debateu, tendo por cenário a realização de projeções até meados do século XXI, sobre o consumo, as reservas de recursos naturais não renováveis e o crescimento da população no mundo. Ainda, 
em 1968, a Organização das Nações Unidas, em sua XXIII Assembleia Geral, através da Resolução n. ${ }^{\circ}$ 2.398, convocou a realização de Conferência sobre o Meio Ambiente Humano, a qual foi realizada alguns anos mais tarde. Nesse momento é que o Direito Ambiental Internacional (DAI) começou a se formatar, ao prever o termo meio ambiente num documento internacional específico.

Influenciado por esse cenário, na década de 70, a partir das conclusões desenvolvidas no encontro do Clube de Roma, elaborou-se, com a colaboração de diversos autores, em 1972, o livro The Limits to Growth (Limites do Crescimento), coordenado por Dennis Meadows e por Donella H. Meadows (sendo que em razão dos nomes desse casal, ele também passou a ser reconhecido como Relatório Meadows). Com sua edição, foram reconhecidos, publicamente, em âmbito internacional, vários dos problemas ambientais que tendiam a assolar a humanidade (como a insuficiência de alimentos, o crescimento populacional, entre outros) e que demandavam revisões (em especial, limitações) nos modelos políticos e econômicos de crescimento. (MEADOWS, 2006).

Nessa senda, em sequência, foi em 1972, que se realizou a Conferência das Nações Unidas sobre o Meio Ambiente Humano em Estocolmo (na Suécia), que reuniu 113 países (entre eles, encontrava-se o Brasil). É a primeira vez que, em âmbito internacional, numa conferência, trata-se, especificamente, sobre o meio ambiente e sobre a relação do homem com ele. Esse evento passou a ser definido, então, como o marco inicial do Direito Ambiental Internacional (DAI). (ONU, 1972).

Um dos principais pontos de discussão, na Conferência de Estocolmo, relacionou-se à questão ambiental e ao desenvolvimento, ${ }^{4}$ sendo que, durante os trabalhos, surgiram duas correntes de pensamento sobre o tema: a preservacionista ou zerista (composta por países desenvolvidos que defendiam a não intervenção do homem no meio) e a desenvolvimentista (integrada pelos países em desenvolvimento favoráveis ao crescimento econômico, mesmo que ele causasse poluição ou qualquer outro tipo de degradação ambiental - vinculando-se o Brasil a esse posicionamento). Vale explicar que o subdesenvolvimento, para esta última

\footnotetext{
${ }^{2}$ Químico denominado diclorodifeniltricloruetano (DDT), bastante utilizado após a Segunda Guerra Mundial, já que foi criado a partir de conhecimento bélico desenvolvido neste evento, para combater os mosquitos transmissores da malária e do tifo. (CARSON, 1969, p. 163-169).

${ }^{3}$ Em seu início, foi composto por 30 pessoas de países diferentes, como cientistas, educadores, economistas, humanistas, industriais, funcionário públicos, entre outros. (MCCORMICK, 1992, p. 86).
} 
corrente, era considerado como um problema, relacionado a diversos encargos sociais, como alimentação, moradia, saúde, entre outros; por isso, o interesse dos países de $3^{\circ}$ mundo pelo crescimento econômico a qualquer custo, a fim de que as condições de vida da população, com a prosperidade econômica, melhorassem. Em análise geral, apesar desse conflito, entende-se que o resultado do encontro foi positivo. (SOARES, 2003, p. 86-92; RIBEIRO, 2001, p. 23-34).

Ao seu término, editou-se a Declaração de Estocolmo sobre Meio Ambiente Humano, cujos 26 princípios foram os responsáveis por delinearem o ambientalismo na época (entendido, nas palavras de Maurice Strong, secretário-geral da Conferência de Estocolmo, que abriu o evento, como um "[...] novo movimento de libertação", o qual objetivava emancipar o homem dos perigos ambientais produzidos por ele mesmo). A declaração de Estocolmo acabou por não trazer a definição de meio ambiente (apesar de categorizá-lo, em sentido lato sensu, como natural e artificial), mas, através de uma visão antropocêntrica, destacou a relação do homem com ele não como um objeto de interesse, mas sim como um objeto de proteção. Além do que, no princípio $2^{\circ}$, ela reconheceu o direito fundamental do homem a condições de vida adequada. Logo, pode-se entender que essa disposição, em seus termos, representa o direito humano ao meio ambiente. (SACHS, 2008, p. 13-19).

Em seu considerando, estabelece a Declaração de Estocolmo que "a proteção e o melhoramento do meio ambiente humano é uma questão fundamental que afeta o bem-estar dos povos e o desenvolvimento econômico do mundo inteiro, um desejo urgente dos povos de todo o mundo e um dever de todos os governos”. Já, são os princípios - muitos deles expressos pela primeira vez, como o do poluidor-pagador, da prevenção, da cooperação, entre outros - constantes no texto dela:

\footnotetext{
${ }^{4}$ Convém diferenciar desenvolvimento e crescimento econômico, sendo aquele mais amplo do que este: "o crescimento é uma condição necessária, mas de forma alguma suficiente (muito menos é um objetivo em si mesmo) para se alcançar a meta de uma vida melhor, mais feliz e mais completa para todos". (SACHS, 2008. p. 13).
} 
Tabela 1: Síntese dos princípios da Declaração de Estocolmo, 1972

\begin{tabular}{|c|c|}
\hline Número & Conteúdo \\
\hline Princípio $1^{\circ}$ & Direito fundamental a um meio ambiente de qualidade; \\
\hline Princípio $2^{\circ}$ & $\begin{array}{l}\text { Preservação dos recursos para as futuras gerações (sujeitos } \\
\text { beneficiados); }\end{array}$ \\
\hline Princípio $3^{\circ}$ & Manutenção da reprodução dos recursos renováveis; \\
\hline Princípio $4^{\circ}$ & $\begin{array}{c}\text { Responsabilidade humana em preservar e administrar o } \\
\text { patrimônio ambiental; }\end{array}$ \\
\hline Princípio $5^{\circ}$ & $\begin{array}{l}\text { Promoção de um uso dos recursos não renováveis que evite } \\
\text { o seu esgotamento; }\end{array}$ \\
\hline Princípios $6^{\circ}$ e $7^{\circ}$ & Combate à poluição; \\
\hline Princípio $8^{\circ}$ & Desenvolvimento econômico e social; \\
\hline Princípio $9^{\circ}$ & $\begin{array}{l}\text { Desenvolvimento acelerado mediante assistência financeira } \\
\text { e tecnológica; }\end{array}$ \\
\hline Princípio $10^{\circ}$ & $\begin{array}{l}\text { Estabilidade de preços e pagamento adequado das } \\
\text { commodities; }\end{array}$ \\
\hline Princípio $11^{\circ}$ & $\begin{array}{l}\text { Compatibilização das políticas ambientais com o potencial } \\
\text { desenvolvimentista dos países; }\end{array}$ \\
\hline Princípio $12^{\circ}$ & $\begin{array}{l}\text { Destinação de recursos à preservação e à melhora ambiental } \\
\text { dos países em desenvolvimento; }\end{array}$ \\
\hline Princípios $13^{\circ}$ e $14^{\circ}$ & Planejamento dos processos de desenvolvimento; \\
\hline Princípio $15^{\circ}$ & Planejamento dos agrupamentos urbanos; \\
\hline Princípio $16^{\circ}$ & Políticas demográficas; \\
\hline Princípio $17^{\circ}$ & $\begin{array}{l}\text { Papel das instituições nacionais na gestão dos recursos } \\
\text { ambientais; }\end{array}$ \\
\hline
\end{tabular}

\begin{tabular}{|c|c|}
\hline Princípio $18^{\circ}$ & Papel da ciência e tecnologia; \\
\hline Princípio $19^{\circ}$ & Educação para as questões ambientais; \\
\hline Princípio $20^{\circ}$ & $\begin{array}{c}\text { Pesquisa e desenvolvimento científicos referentes aos } \\
\text { problemas ambientais; }\end{array}$ \\
\hline Princípio $21^{\circ}$ & $\begin{array}{c}\text { Direito soberano dos Estados de explorarem seus próprios } \\
\text { recursos naturais e obrigação de não causarem danos aos } \\
\text { outros Estados }\end{array}$ \\
\hline Princípios $22^{\circ}, 24^{\circ}$ e $25^{\circ}$ & Cooperação; \\
\hline Princípio $23^{\circ}$ & Adaptação dos padrões ambientais à realidade de cada país; \\
\hline Princípio $25^{\circ}$ & Necessidade de um acordo sobre armas nucleares. \\
\hline
\end{tabular}

Fonte: Adaptada pelos autores de Villar (2015).

Convém mencionar que a Carta de Estocolmo é considerada a Declaração de Princípios do Meio Ambiente. Possui como efeito o atrelamento de todos os tratados anteriores e posteriores ambientais à observância dos mandamentos nela estabelecidos. Em outras palavras, ela é responsável por dar suporte às normas jurídicas ambientais. Quanto a sua natureza jurídica, deve-se atentar para o fato de que as declarações internacionais também são normas de direito internacional, ainda que dotadas, em sua configuração, de diferenças 
formais e materiais em comparação a outras fontes, ao núcleo duro (hard law), do direito internacional. Por isso, sua importância não deve ser reduzida e seu conteúdo não deve ser desconsiderado, já que possui normatividade, sendo um documento relevante para o direito ambiental internacional. (BIRNIE; BOYLE, 2002, p. 34-47). Inclusive, foi o conteúdo da Declaração de Estocolmo que influenciou a elaboração e as disposições da Lei n. ${ }^{\circ} 6.938$ em 1981 (a qual estabelece a Política Nacional de Meio Ambiente brasileira), bem como motivou a disciplina da norma ambiental constitucional cerne, artigo 225, da Constituição da República Federativa do país em 1988, afinal, na época, ela era o único grande arquivo de referência sobre o assunto. (DERANI, 1997, p. 256).

Importa frisar que dessa conferência resultou, também, o Programa das Nações Unidas para o Meio Ambiente (PNUMA), estabelecido pela Assembleia Geral da ONU em 1972 (mas que entrou em vigor, apenas, em 1973), o qual tem como espoco a promoção das diretrizes de Estocolmo. Ainda, nesse período, elaborou-se o termo ecodesenvolvimento, que, primeiramente, pela concepção de Maurice Strong (quem o criou), referia-se, com enfoque aos países emergentes, à relação existente entre o meio ambiente e o desenvolvimento, como alternativa aos ideais de "crescimento zero" e de "crescimento a qualquer custo", com base no trinômio "[...] eficiência econômica, equidade social e equilíbrio ecológico". Posteriormente, Ignacy Sachs, em 1973, ressignificou a mencionada expressão, com fundamento na qualidade (e não, simplesmente, na quantidade) de crescimento, com escopo de avaliar estratégias capazes de harmonizar o desenvolvimento socioeconômico e a gestão ambiental, considerando, inclusive, nesse vínculo, o conhecimento produzido pelas populações locais. (SACHS, 2008, p. 19-33).

Diante do exposto, convém salientar que a Conferência de Estocolmo foi o acontecimento isolado que mais influenciou o reconhecimento do movimento ambientalista em nível internacional; assim, esse deixou de ser tratado, apenas, como marginal ou acadêmico, passando a ser inserido na esfera pública, inclusive como um subsistema próprio do Direito Internacional: o Direito Ambiental Internacional (DAI). Foi a partir dela que o meio ambiente integrou, permanentemente, a agenda de preocupações mundiais, pois seu status foi elevado a de direito humano-fundamental e, também, foi legitimado como necessário para a efetividade de outros direitos da pessoa humana. $\mathrm{O}$ ambientalismo, a partir de então, difundiu-se como um movimento mais racional, ativista, político e global.

(CASTELLS, 2001, p. 23-25; SOARES, 2003, p. 18-20).

Nesse contexto, convém referir que: 


\begin{abstract}
A Assembleia Geral das Nações Unidas recebeu a Declaração pela resolução 2994 (XXVII). Nesta ocasião, também, adotou a resolução 2995 (XXVII), que estabeleceu a cooperação dos estados em matéria ambiental, e a resolução 2996 (XXVII), que explicitou a responsabilidade internacional dos Estados nas questões ambientais. Após esta data, foram profícuos os tratados multilaterais, bilaterais, declarações, acordos regionais, comitês científicos estabelecidos no campo internacional para cuidar da questão ambiental, constituindo um corpo normativo com características próprias, pelo objeto, princípios, práticas e sujeitos; porém guardando intrínseca conexão com o direito internacional, por seus princípios, sujeitos, práticas, documentos e instituições. (grifo meu). (DERANI, 2014, p. 14).
\end{abstract}

Em sequência à Conferência de Estocolmo, em 1973, elabora-se a primeira convenção pós-Estocolmo (com base nos princípios ambientais elaborados nesta conferência): sobre o Comércio Internacional das Espécies da Fauna e Flora Silvestres Ameaçadas de Extinção (CITES), visando regulamentá-lo (o que não significa impedi-lo). Por sua vez, em 1976, outro grande desastre ambiental ganha repercussão mundial: é o caso da contaminação atmosférica acarretada pelo rompimento de tanques de armazenagem de indústria química em Seveso, na Itália, a qual ocasionou a morte de milhares de animais. Perante esse conjunto de acontecimentos, a questão ambiental, em âmbito internacional, cada vez mais, ficava em foco. (SCHWABACH, 2006).

Assim, em 1983 surge o primeiro partido Verde da história na Alemanha, denominado de Die Grünen, que chegou ao parlamento, defendendo, entre as várias propostas de sua plataforma, a ecologia. A partir de então, ele se expandiu para outros países, como a Nova Zelândia e a Suécia. Ainda, em 1986, ocorre o acidente nuclear de Chernobil, na Ucrância, então União Soviética (em pleno regime socialista), com mortes e contaminação (de animais, do solo, das águas, entre outras) por material radioativo decorrentes da explosão do reator 4 da referida usina. Esse evento, inclusive, é um dos únicos classificados, na história, como de nível 7, que é a escala de grau mais elevado de acidentes nucleares . Por sua vez, em 1989, foi a vez dos Estados Unidos enfrentarem a tragédia de Bhopal, na qual gases tóxicos, que vazaram de dutos de fábrica de pesticida, acarretaram milhares de óbitos, sendo que várias pessoas (por exemplo, muitas crianças que nasceram naquela localidade) possuem sequelas, por terem tido contato, ainda que indireto, com os efeitos do acidente. Ou seja, novamente, em âmbito internacional, apesar do Direito Ambiental Internacional já ter começado a dar seus primeiros passos nessa época, novos graves desastres ambientais voltaram a ocorrer. (CASTELLS, 2001, p. 102; SCHWABACH, 2006).

Nesse contexto, passados 10 anos da realização da Conferência de Estocolmo, em 
1982, a IUCN (International Union for Conservation of Nature) preparou a Carta Mundial da Natureza, a qual foi publicada, no mesmo ano, por Resolução da Assembleia Geral da ONU (Res/37/48), reforçando os princípios da declaração sobre Meio Ambiente Humano (1972). Nela, destacou-se a relação vital existente entre o homem e o ambiente, com alguns elementos que remetiam à sustentabilidade, sendo que esta ganhou corpo, em âmbito internacional, somente alguns anos mais tarde. (IUCN, 1982).

Nessa senda, na década de 80 , as discussões iniciadas sob a perspectiva do ecodesenvolvimento passaram a ser avaliadas sob a premissa do desenvolvimento sustentável, ${ }^{5}$ o que influenciou as ações dos movimentos e do Direito Ambiental Internacional. Convém destacar que o desenvolvimento sustentável tem sua designação como tal atrelada ao documento Nosso Futuro Comum (também conhecido como Relatório Brundtland), publicado em 1987, pela Comissão Mundial sobre Meio Ambiente e Desenvolvimento (CMMAD). Salienta-se que esse diploma foi resultado das discussões ocorridas na Conferência das Nações Unidas para o Meio Ambiente (1972) em Estocolmo, bem como da criação, em 1983, da Comissão Mundial sobre Meio Ambiente e Desenvolvimento. ${ }^{6}$ Nele, o desenvolvimento sustentável é subscrito como um princípio, nos seguintes termos: "o desenvolvimento que satisfaz as necessidades presentes, sem comprometer a capacidade das gerações futuras de suprir suas próprias necessidades". Dessa forma, ele estaria assentado em três pilares: economia, sociedade e meio ambiente. ${ }^{7}$ Assim, frente à análise dessa relação intrínseca entre a natureza e o desenvolvimento e da necessidade de sua compatibilização, recomendou-se, para um maior aprofundamento do tema, que a Assembleia Geral da ONU convocasse a II Conferência Internacional de Meio Ambiente e

\footnotetext{
${ }^{5}$ O desenvolvimento sustentável, em âmbito internacional, tem a origem de sua previsão formal na Declaração de Cocoyoc (1974), produzida a partir de um simpósio de especialistas, ocorrido no México (cidade de Cocoyoc) e promovido pelo Programa das Nações Unidas para o Desenvolvimento (PNUD) e pela Conferência das Nações Unidas sobre Comércio e Desenvolvimento (UNCTAD). Importa ressaltar que, anteriormente ao Relatório Brundtland, ainda que com menor expressão, em 1980, a União Internacional para a Conservação da Natureza publicou o texto A estratégia global para a conservação, em que o tema já era previsto. Da mesma forma, a Resolução ${ }^{\circ}$. 44/228, de 22 de dezembro de 1989, da Assembleia Geral das Nações Unidas, a qual previu a convocação da Conferência sobre Meio Ambiente e Desenvolvimento, também mencionava o princípio do desenvolvimento sustentável. Contudo, foi a partir da Declaração do Rio sobre Meio Ambiente e Desenvolvimento, documento produzido em decorrência da Eco-92, que ele ganhou reconhecimento. Também, foi incorporado à Agenda 21, recebendo tratamento bastante pormenorizado, através da adoção de "uma verdadeira política ambiental com as esferas do planejamento e da economia" ou, em outras palavras, por meio da "construção de uma ponte entre as necessidades do desenvolvimento e a proteção do meio ambiente" Assim, ele se disseminou em cartas internacionais subsequentes, como na Declaração Ministerial da Organização Mundial do Comércio (OMC) de 2001, consolidando-se em razão da sua importância. (WINTER, 2009, p. 02-05).
} 
Desenvolvimento, o que culminou na promoção da Eco-92, no Rio de Janeiro. (CMMAD, 1987, PNUMA, 2011).

Nesse interstício temporal, convém mencionar que outros importantes documentos internacionais foram elaborados, como o Protocolo de Montreal sobre Substâncias que Destroem a Camada de Ozônio (1987) e a Convenção de Basileia sobre o Controle de Movimentos Transfronteiriços de Resíduos Perigosos e seu Depósito (1989), entre outras. Faz-se mister informar que essas convenções, assim como a CITES, que foram produzidos entre as realizações de Estocolmo e a Rio-92, interferiram no comércio livre, ou seja, no pleno liberalismo, em prol da proteção ambiental. (SOARES, 2003, p. 38-40).

Nessa senda, diante do ápice da preocupação ambiental em nível mundial, a ONU declarou 1990 como o Ano Internacional do Meio Ambiente. ${ }^{8}$ A partir dele, o ambientalismo caracterizou-se como de gestão articulada entre o poder público, a sociedade e o empresariado, com base na ecoeficiência. Isso se deveu, principalmente, a realização da Conferência das Nações Unidas sobre Meio Ambiente e Desenvolvimento (CNUMAD) também conhecida como Rio-92, Eco-92 ou Cúpula da Terra (Earth Submmit) - em que, na presença de 193 países, buscou-se uma cooperação internacional para a consolidação do desenvolvimento sustentável. 9 Nesse momento, consolida-se o Direito Ambiental Internacional. Convém destacar que a sociedade civil organizada participou ativamente dessa conferência através de um evento paralelo, denominado de Fórum Global 92, que contou com a presença de, aproximadamente, um mil e quatrocentas ONGs. A atuação foi positiva, pois, mediante pressão, foi possibilitada a inserção de alguns temas que não estavam previstos

\footnotetext{
${ }^{6}$ Essa era uma comissão independente, aprovada pela Assembleia Geral da ONU, com os objetivos de examinar questões atinentes à matéria ambiental e incentivar a cooperação internacional, sendo coordenada pela então primeira-ministra da Noruega: Gro Harlen Brundtland. Por esse motivo, o documento Nosso Futuro Comum, cuja criação foi recomendada pela CMMAD é conhecido, também, como Relatório Brundtland. (PNUMA, 2011).

${ }^{7} \mathrm{Em}$ aspecto crítico, entende-se que o pressuposto "três pilares" da sustentabilidade - o qual demonstra que o meio ambiente, a economia e a sociedade "devem coexistir como entidades equivalentes" e em caso de conflito devem ser, portanto, "balanceados" - é inapropriado. Nesse sentido, seu quadro representativo correto dar-se-ia por "[...] um fundamento e dois pilares apoiando-o", com vistas (portanto, tendo como "telhado", na formatação de uma figura similar a uma casa), as futuras gerações (o que se denomina de "políticas a serem verificadas no futuro"). Passa-se a explicar essa "simbologia". Nessa, sua base é representada pela biosfera, "a qual é de 'fundamental' importância". Já, seus dois pilares correspondem à economia e à sociedade, que "são parceiros mais fracos, pois a biosfera pode existir sem humanos, mas os humanos certamente não podem existir sem a biosfera". Ainda, enquanto no conceito de três pilares, procuram-se "negociações duradouras" (pois ele "não se empenha a curto prazo, tendo em vista as consequências ganhas a longo prazo"), no de dois pilares entende-se que "sacrifícios da natureza, utilizados para o destaque na economia a curto prazo ou para interesses sociais, podem tornar-se destrutivos para a própria economia e sociedade, a longo prazo". (WINTER, 2009, p. 04-06).

${ }^{8}$ Uma estatística impressionante, dos anos 1990, é que nessa época "[...] 80\% dos norte-americanos e mais de dois terços dos europeus consideravam-se ambientalistas". (CASTELLS, 2001, p. 141).
} 
inicialmente na pauta de negociações. Ao término da conferência, por sua vez, foram produzidos os seguintes documentos internacionais: Declaração do Rio sobre Meio Ambiente e Desenvolvimento, Agenda 21, Convenção-Quadro sobre Mudanças Climáticas e Convenção sobre Diversidade Biológica ou da Biodiversidade. (SACHS, 2008, p. 34-48; CNUDS, 2012).

Convém explicar que a Declaração do Rio de Janeiro (1992) não traz definição, assim como a de Estocolmo (1972), de meio ambiente. Por sua vez, ela é um pouco mais extensa do que a anterior; porém não se evidenciam grandes alterações em seu conteúdo, havendo a inserção, em seu texto, de, apenas, alguns princípios diferentes dos presentes naquela, como do desenvolvimento sustentável, da precaução, entre outros. Nessa senda, explica-se que:

\begin{abstract}
A Declaração do Rio pode não ter a força impositiva dos Tratados, mas é o mais forte parâmetro ético de comportamento dos Estados e das instituições internacionais em termos de apropriação global dos recursos naturais e responsabilidade comum pela conservação do meio ambiente e promoção do desenvolvimento econômico, social e cultural de modo sustentável. (DERANI, 2014, p. 16).
\end{abstract}

Nesse sentido, segue a síntese dos princípios dela (Tabela 02) para que se possa compará-los com a Tabela 01 (referente aos princípios da Declaração de Estocolmo, a qual foi apresentada acima):

Tabela 2: Síntese dos Princípios da Declaração do Rio de Janeiro, 1992

\begin{tabular}{|c|c|}
\hline Número & Conteúdo \\
\hline Princípio $1^{\circ}$ & $\begin{array}{l}\text { Seres humanos no centro do } \\
\text { Desenvolvimento Sustentável (DS), direito a vida } \\
\text { saudável, produtiva e em harmonia com a natureza; }\end{array}$ \\
\hline Princípio $2^{\circ}$ & $\begin{array}{l}\text { Direito soberano dos Estados explorarem seus } \\
\text { próprios recursos naturais e responsabilidade } \\
\text { de não causar dano; }\end{array}$ \\
\hline Princípio $3^{\circ}$ & Necessidades das gerações futuras; \\
\hline
\end{tabular}

\footnotetext{
${ }^{9}$ Ainda, nesse período (1995), fundou-se, com a participação de 48 empresários e 28 países, o Business Council for Sustainable Development (BCSD) (Conselho Empresarial Mundial para o Desenvolvimento Sustentável), o qual tinha por objetivo formular o posicionamento deles sobre o desenvolvimento sustentável e, principalmente, estimular o seu interesse e a sua atuação com base nele. (PNUMA, 2011).
} 


\begin{tabular}{|c|c|}
\hline Princípio $4^{\circ}$ & $\begin{array}{l}\text { Proteção ambiental como parte do Desenvolvimento } \\
\text { Sustentável; }\end{array}$ \\
\hline Princípio $5^{\circ}$ & Cooperação para erradicação da pobreza; \\
\hline Princípio $6^{\circ}$ & $\begin{array}{c}\text { Prioridade para as necessidades dos países em } \\
\text { desenvolvimento; }\end{array}$ \\
\hline Princípio $7^{\circ}$ & $\begin{array}{c}\text { Cooperação para a saúde e integridade do ecossistema } \\
\text { terrestre; }\end{array}$ \\
\hline Princípio $8^{\circ}$ & $\begin{array}{c}\text { Combate aos padrões insustentáveis de produção } \\
\text { e consumo e política demográfica; }\end{array}$ \\
\hline Princípio $9^{\circ}$ & Cooperação técnica; \\
\hline Princípio $10^{\circ}$ & Participação social; \\
\hline Princípio $11^{\circ}$ & Legislações ambientais eficientes; \\
\hline Princípio $12^{\circ}$ & $\begin{array}{l}\text { Promoção de um sistema econômico } \\
\text { internacional aberto e favorável; }\end{array}$ \\
\hline Princípio $13^{\circ}$ & $\begin{array}{l}\text { Legislações nacionais para responsabilizar os } \\
\text { poluidores e indenizar as vítimas; }\end{array}$ \\
\hline Princípio $14^{\circ}$ & $\begin{array}{l}\text { Cooperação para combater a realocação e transferência } \\
\text { de atividades ou substancias nocivas; }\end{array}$ \\
\hline Princípio $15^{\circ}$ & Princípio da precaução; \\
\hline Princípio $16^{\circ}$ & $\begin{array}{l}\text { Internacionalização dos custos ambientais e } \\
\text { uso de instrumentos econômicos; }\end{array}$ \\
\hline Princípio $17^{\circ}$ & Avaliação de impacto ambiental; \\
\hline Princípio $18^{\circ}$ & $\begin{array}{c}\text { Dever de notificar sobre desastres naturais ou } \\
\text { situações de emergência; }\end{array}$ \\
\hline Princípio $19^{\circ}$ & $\begin{array}{c}\text { Dever de notificar previamente, fornecer } \\
\text { informações e realizar consultas no caso de } \\
\text { atividades que possam gerar efeitos } \\
\text { transfronteiriços; }\end{array}$ \\
\hline Princípios $20^{\circ}, 21^{\circ}$ e $22^{\circ}$ & $\begin{array}{c}\text { Papel das mulheres; jovens; povos indígenas e } \\
\text { comunidades endógenas na temática } \\
\text { ambiental; }\end{array}$ \\
\hline Princípio $23^{\circ}$ & Proteção ambiental dos povos oprimidos; \\
\hline Princípio $24^{\circ}$ & $\begin{array}{l}\text { Proteção ambiental durante conflitos } \\
\text { armados; }\end{array}$ \\
\hline Princípio $25^{\circ}$ & $\begin{array}{l}\text { Interdependência entre a paz, desenvolvimento e proteção } \\
\text { ambiental; }\end{array}$ \\
\hline Princípio $26^{\circ}$ & Solução pacífica das controvérsias; \\
\hline Princípio $27^{\circ}$ & Cooperação com base na boa fé. \\
\hline
\end{tabular}

Fonte: Adaptada pelos autores de Villar (2015).

Dando sequência a essas ações, em 1997, em Nova Iorque (EUA), com a presença de chefes de Estado, e no Rio de Janeiro (BRA), a partir da coordenação de ONGs, foram realizadas reuniões intituladas Rio +5 , as quais tiveram por objetivo avaliar os resultados dos compromissos assumidos, passados cinco anos, na Rio-92. Na época, infelizmente, entendeuse que os avanços foram poucos. Após dez anos desta (Rio-92) e cinco anos da Rio+5, em 2002, ocorreu a Conferência Mundial para o Desenvolvimento Sustentável (ou Rio+10) em Johanesburgo, na África do Sul, onde reuniram-se, novamente, os países para a discussão dos efeitos das conferências anteriores, bem como para o estabelecimento de (c) (†) (5) 
compromissos visando a proteção dos recursos naturais do planeta e a alteração dos padrões de consumo e de produção. Contudo, o conteúdo da declaração produzido ao término dessa conferência foi decepcionante, pois não conseguiu avançar na discussão ambiental em nível internacional. Importa salientar que, a ausência de reprodução de princípios constantes nos documentos das outras conferências pelo documento final desta, não significa que eles foram derrogados. (ONU, 1992).

Já, em 2012, em continuidade aos movimentos ambientalistas, ocorreu a Conferência das Nações Unidas sobre Desenvolvimento Sustentável (CNUDS), denominada, também, de Rio+20, sediada na cidade do Rio de Janeiro/RJ no Brasil, na presença de 190 países (foi o maior dos eventos promovidos em matéria ambiental internacional), buscando a renovação dos compromissos políticos e econômicos com o desenvolvimento sustentável através da adoção de uma governança ambiental global (a qual, lamentavelmente, deixou a desejar, pois a aprovação de seu documento final, O Futuro que Queremos, apesar de mais completo que o de Johanesburgo (até mesmo a estrutura dos dois documentos é muito distinta), ocorreu com a manifestação de reservas de vários países sobre assuntos importantes - entre eles, o direito à água). Ponto positivo foi a participação da sociedade civil e de movimentos sociais na Cúpula dos Povos, evento paralelo a Rio+20, no qual se discutiu sobre os problemas socioambientais e a necessidade do contínuo fortalecimento do ativismo. Durante a CNUDS, portanto, além de questões ambientais, foram abordadas adversidades sociais, como a falta de moradia, saneamento básico etc., com o intuito de se reforçar a relação indissociável entre meio ambiente, vida digna e sustentabilidade. (CNUDS, 2012).

Convém observar que, mesmo diante desse aumento da sistematização do Direito Ambiental Internacional, grandes desastres ambientais continuaram a ocorrer (como é o caso de Fukushima em 2011). Nesse sentido, faz-se necessário efetivá-lo e ampliá-lo mais, porque várias questões ainda carecem de uma forte proteção ambiental em âmbito internacional, como é o caso da água. Em suma, diante do exposto, traça-se uma linha do tempo com alguns dos acontecimentos mais importantes, acima explicados, no cenário internacional, pré e pósEstocolmo, que influenciaram a emergência do Direito Ambiental Internacional, inclusive, consolidando-o. Em sequência, dentro desse cenário de formatação do DAI, analisa-se, pormenorizadamente, o caso das Fábricas de Celulose ocorrido no Uruguai, o qual foi julgado pela Corte Internacional de Justiça (CIJ) em 20 de abril de 2010. 
Figura 01: Linha histórica de alguns importantes acontecimentos, pré e pós-Estocolmo, no contexto internacional, que influenciaram a emergência e consolidaram o Direito Ambiental Internacional (DAI)

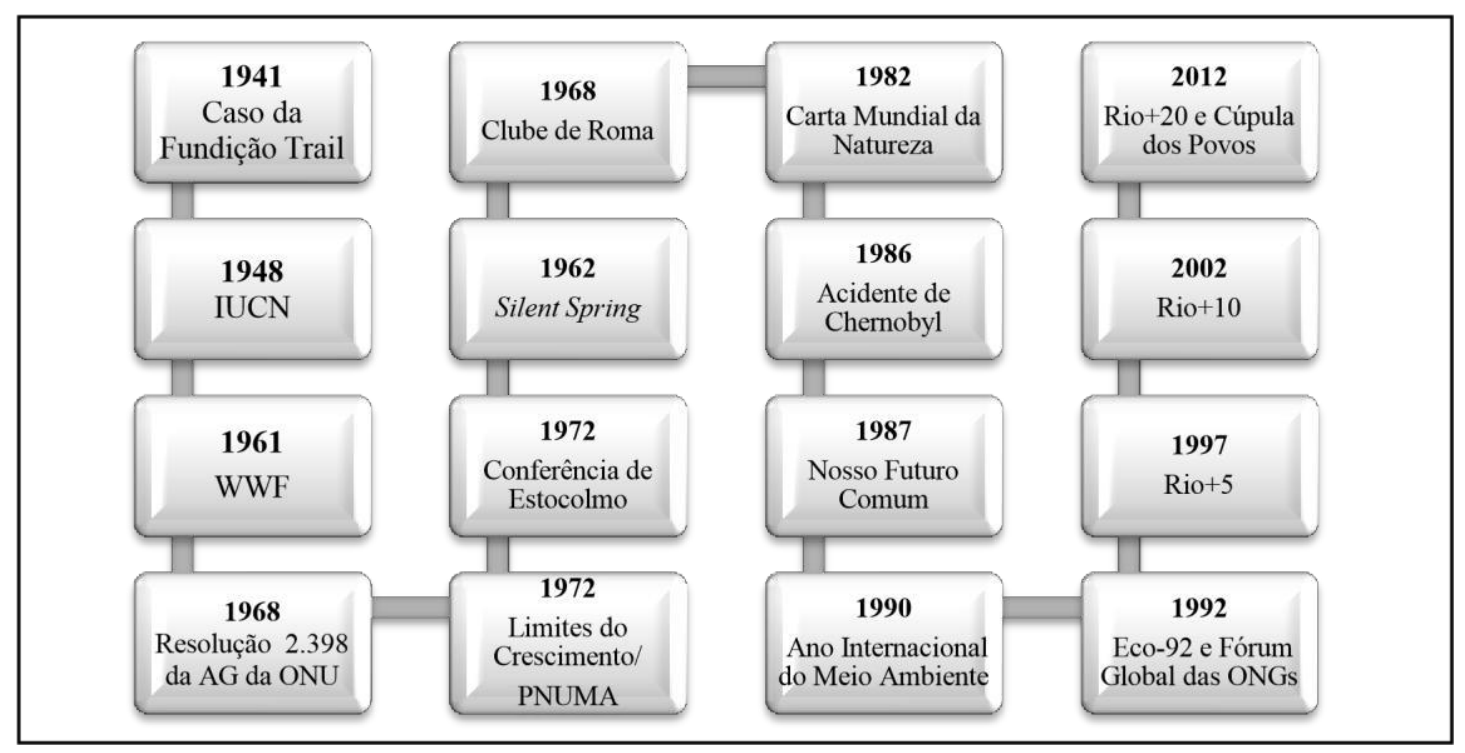

Fonte: Elaborada pelos autores.

\section{AS FÁbRICAS DE CELULOSE (PULP MILLS) NO RIO URUGUAI: A} APLICAÇÃO DE PRINCÍPIOS E DE REGRAS DO DIREITO AMBIENTAL INTERNACIONAL EM SUA DECISÃO PELA CORTE INTERNACIONAL DE JUSTIÇA

As fábricas de celulose (Pulp Mills) inserem-se entre um dos principais casos do Direito Ambiental Internacional. Ele, que é recente (já que suas discussões emergiram a partir dos anos 2000), teve como partes Argentina e Uruguai, sendo que aquela buscava a preponderância da proteção ambiental - visto que os danos causados pela instalação e operacionalização das papeleiras refletiriam em seu território - em detrimento do crescimento econômico, a qualquer custo, uruguaio. Temas como avaliação de impacto ambiental, desenvolvimento sustentável, recursos compartilhados, deveres e responsabilidades para o equilíbrio ecológico, entre tantos outros, podem ser encontrados na decisão prolatada pela Corte Internacional de Justiça (CIJ) em 2010. Diante dessas linhas introdutórias, convém serem apresentados, primeiramente, os fatos que acarretaram o conflito entre os referidos países para, posteriormente, proceder a sua análise jurídica.

Assim, inicialmente, em julho de 2002, empresários do grupo CMB/ENCE (Empresa Nacional de Celulose da Espanha) contataram o governo uruguaio propondo a ele a construção de uma fábrica de pasta de celulose na margem esquerda do Rio Uruguai (no 
departamento de Rio Negro, na porção leste do município de Fray Bentos). Convém mencionar que essa companhia já era proprietária, na referida cidade, de uma indústria de processamento de madeira, possuindo, na região, inclusive, uma floresta de eucaliptos de, aproximadamente, duzentos mil hectares. Assim, foi essa situação que motivou a escolha do local para a possível instalação e operacionalização da Celulosa M'Bopicuá (CMD). Visando a consolidação do projeto, os representantes da ENCE informaram a CARU (Comissão de Administração do Rio Uruguai) sobre ele, a qual, então, solicitou ao Ministro do Meio Ambiente do Uruguai, vistas dele, em especial, do Estudo de Impacto Ambiental (EIA). (CIJ, 2010).

A CARU, de posse dessas informações, realizou audiência pública em 15 de agosto de 2003. Posteriormente a ela, a Comissão solicitou ao Uruguai esclarecimentos em relação a diversos aspectos do projeto. Apesar de não terem sido sanadas essas questões (pois o Uruguai não encaminhou à CARU os documentos solicitados), em sequência, em 09 de outubro de 2003, MVOTMA (Ministério de Vivienda, Ordenamiento Territorial y Medio Ambiente do Uruguay) concedeu autorização para a construção da fábrica CMB/ENCE. Dessa forma, em 17 de outubro de 2003, em sessão extraordinária da CARU, o governo argentino cobrou o cumprimento de obrigações previstas no Tratado do Rio Uruguai (1975) ${ }^{10}$ que não estariam sendo observadas. Diante disso, objetivando demonstrar que estava atuando de forma legal, em 27 de novembro de 2003, o Uruguai remeteu cópias do EIA e da sua autorização ambiental prévia para a Argentina. Esta, por sua vez, respondeu alegando que eles não estavam em conformidade com o que previa o Estatuto do Rio Uruguai. Após outras turbulentas manifestações, em 28 de novembro de 2005, já dotados de autorização uruguaia para a realização de trabalhos preparatórios para a construção da $\mathrm{CMB} / \mathrm{ENCE}$, os proponentes do projeto solicitaram a suspensão dele por noventa dias, o que culminou, em 21 de setembro de 2006, na desistência da empresa espanhola em executá-lo. (CIJ, 2010).

De outro lado, a empresa finlandesa Oy Metsä-Botnia AB-BOTNIA, em 2004, também manifestou ao Uruguai interesse em construir uma fábrica de celulose em seu território,

\footnotetext{
${ }^{10}$ Nesses termos, convém explicar que a delimitação da fronteira entre a Argentina e o Uruguai foi estabelecida por tratado assinado entre eles (portanto, bilateral) em 1961. Entre as suas disposições, no artigo $7^{\circ}$, encontra-se a previsão de que as partes devem estabelecer um regime para o uso do Rio Uruguai. Para tanto, em 1975, foi criado o Estatuto do Rio Uruguai, visando a sua ótima e racional utilização. Vale mencionar, também, que a CARU, com funções de regulação e coordenação, foi estabelecida por ele. (CIJ, 2010).
} 
denominada de Orion. A região escolhida pela companhia para sua instalação foi a jusante do local em que seria construída a CMB/ENCE. Assim, depois de terem encaminhado ao Governo Uruguaio um dossiê sobre o projeto, seus proponentes reuniram-se, de maneira informal, com integrantes da CARU, em abril de 2004. Realizadas algumas tratativas, em 21 de dezembro de 2004, por recomendação da CARU, o DINAMA (Directorio Nacional del

Medio Ambiente) realizou audiência pública em Fray Bentos, a fim de que se deliberasse sobre Orion. Após essa, por recomendação do DINAMA, MVOTMA expediu autorização ambiental inicial, desde que observadas determinadas condições, em fevereiro de 2005, para a construção da Orion e de um terminal portuário adjacente para uso exclusivo da fábrica. (CIJ, 2010).

Diante dessa situação, a Argentina passou a manifestar sua inconformidade com o Uruguai, alegando descumprimento de obrigações de prévia comunicação à CARU sobre a alteração do regime do rio e/ou da qualidade de suas águas (que é o disposto no artigo $7^{\circ}$ do Estatuto do Rio Uruguai) e de notificação das suas intenções negociais e das suas consequências para o governo argentino. Mesmo diante dessas reclamações, o Uruguai, em 12 de abril de 2005, autorizou as obras de fundação e de seus acessórios pela AB-BOTNIA. Já, em 31 de maio de 2005, buscando a viabilização de um acordo entre os Estados relativo à construção da fábrica, foi criado o Grupo Técnico de Alto Nível (GTAN). Entretanto, as negociações nele fracassaram. Nessa senda, após as autorizações definitivas dadas pelo Uruguai para a fábrica e para o terminal portuário, Orion foi construída e está em funcionamento desde 09 de setembro de 2007. (CIJ, 2010).

Perante esse cenário, a Argentina, então, ingressou na Corte Internacional de Justiça (CIJ), em 04 de maio de 2006, contra o Uruguai. As partes concordaram sobre a jurisdição da Corte, apesar de divergirem sobre os limites da sua competência. ${ }^{11}$ Em linhas gerais, os pedidos da Argentina abarcavam as autorizações concedidas pelo governo uruguaio para a construção, em seu território, da CMB/ENCE e para a instalação e funcionamento da Botnia (sendo que o porto de Nova Palmira não foi incluído na discussão). Sua motivação assentavase nas constatações de que as atividades das papeleiras tendiam a acarretar reflexos danosos para o meio ambiente argentino, já que a água do Rio Uruguai é um recurso compartilhado. Dessa forma, o Uruguai estaria violando obrigações processuais e materiais previstas no Estatuto (1975). (CIJ, 2010). 
Nesse sentido, mediante essas preocupações, a Argentina formulou pedido de Medidas Provisórias. Contudo, a CIJ manifestou-se no sentido de que não estava convencida, por falta de provas, de que a autorização para a construção das fábricas de celulose representaria danos ambientais, econômicos e sociais irreparáveis para a Argentina, negando-as. Alguns meses depois, Uruguai também formulou pedido de Medidas Provisórias, em razão de bloqueios argentinos - em protestos à construção de Orion - a pontos de acesso (em especial, à ponte General San Martin), o que impedia o fluxo comercial e turístico para a região, acarretando prejuízos econômicos ao país. Nesse sentido, apesar da CIJ reconhecer que os fatos alegados pelo governo uruguaio tinham relação com a causa (objeto) em juízo, deliberou por não as deferir, fundamentando que não houve a comprovação da necessidade urgente de prevenção de danos irreparáveis aos seus direitos. Nesse enfoque, convém informar que a construção de Orion, quando da ocorrência dessa situação que motivou o requerimento de medidas provisórias pelo Uruguai, encontrava-se bastante adiantada. (CIJ, 2010).

Por sua vez, na análise do mérito, quanto à violação das obrigações processuais (ou de procedimento), as quais se relacionam "ao processo de contínuas consultas entre as partes por meio da CARU”, o Estatuto do Rio Uruguai (1975) prevê, como instrumento de cooperação (e, até mesmo, de prevenção), que o Estado o qual planeje alguma atividade em seu território deve, previamente, informá-la para a CARU. Acontece que o Uruguai não cumpriu com seus atos formais de comunicação em relação à CMB-ENCE e nem à ORION/BOTNIA. Assim, ele limitou-se a enviar um resumo para informe público, em 14/11/2004, do EIA relativo à CMB e, da mesma forma, não transmitiu à CARU qualquer documento relativo à ORION/BOTNIA, o que configura descumprimento das obrigações processuais. (BRZEZINSKI, 2012, p. 323).

Ainda, entendeu a CIJ que as negociações realizadas no âmbito do GTAN não supriam as obrigações de informação e notificação violadas pelo Uruguai perante a CARU. Ademais, verificou ela que o Uruguai não aguardou o término do período de negociações (de cento e oitenta dias) para autorizar a construção de Orion. Dessa forma, entre outras discussões, decidiu, por 13 votos a 1 (o posicionamento contrário foi o do juiz ad hoc Torres Bernárdez do Uruguai), que o país violou os mecanismos de cooperação previstos nos artigos $7^{\circ}$ e 12 do Estatuto do Rio Uruguai (1975). (CIJ, 2010).

\footnotetext{
${ }^{11}$ A Corte entendeu que não possui competência, com base no Estatuto do Rio Uruguai (1975), para analisar questões relacionadas à poluição sonora e visual, nem a maus odores. Também, ela decidiu que não havia no Estatuto do Rio Uruguai (1975) a previsão de cláusula de referência, razão pela qual as demais convenções multilaterais invocadas pela Argentina não seriam aplicáveis ao caso. (CIJ, 2010).
} 
Já, quanto às obrigações materiais (substanciais) do Estatuto, após analisadas as questões preliminares sobre o ônus da prova (que ficou decido ser de responsabilidade da Argentina) e sobre a produção de provas técnicas (na qual a CIJ considerou que ela deveria fazer o seu próprio juízo sobre os fatos), foram destacadas: a ótima e racional utilização do Rio Uruguai; o dever de assegurar que o gerenciamento do solo e de florestas não prejudique o regime do rio; a coordenação de medidas para evitar mudanças no equilíbrio ecológico; e, por fim, a prevenção de poluição e de preservação do meio ambiente aquático. Convém mencionar que essas obrigações eram de meio (e não de resultado). Logo, nesse caso, só haveria responsabilização se fossem comprovadas falhas na due diligence na sua atuação, o que, segundo a CIJ, a Argentina não conseguiu fazer. Dessa forma, a sentença acabou por tonar lícitos os atos consumados, numa atitude menos protetiva ao meio ambiente do que se esperava, considerando todo o contexto de formatação, desenvolvimento e concretização de regras e princípios do Direito Ambiental Internacional no século XXI. (CIJ, 2010).

Convém explicar que, nos termos do que já se encontra sedimentado pelo DAI, a utilização ótima e racional do rio, prevista pelo Estatuto de 1975 e explorada pela decisão da CIJ, é fundamental ("pedra angular”) para o regime de cooperação de um bem compartilhado (água), já que é o responsável por estabelecer um equilíbrio entre o direito à sua exploração econômica e o dever de protegê-lo de quaisquer danos decorrentes da atividade (sendo essa máxima, em outras palavras, a essência do princípio do desenvolvimento sustentável). Ainda, as plantações de eucaliptos, matérias-primas das papeleiras, reconhecidamente, possuem potencial de causar prejuízos aos rios e a qualidade de suas águas - não só de forma local, mas transfronteiriça - em razão de influírem negativamente sob a gestão dos solos. Logo, o princípio da prevenção e da preservação do meio ambiente, conjuntamente com a obrigação de execução de uma atuação coordenada das partes, para evitar mudanças no equilíbrio ecológico, foram, também, ressaltados no caso. (CIJ, 2010).

Nesse contexto, faz-se mister salientar o seguinte posicionamento da CIJ em relação às obrigações que impõem às partes adoção de regulamentos e de medidas:

Entende a Corte que [...] as partes têm a obrigação de adotar as regras e as medidas dentro dos seus respectivos sistemas legais e domésticos para proteger e preservar o ambiente aquático e prevenir a poluição. Estas regras e medidas de direito interno devem estar de acordo com os acordos internacionais e com as metas e recomendações de órgãos técnicos internacionais. Assim, a obrigação de preservar o ambiente aquático e de prevenir a poluição são obrigações de conduta, de atuar com due diligence a respeito das atividades que se realizem em seus territórios. A 
responsabilidade internacional de uma das partes do Estatuto do Rio Uruguai só pode ser engajada se ficar provado que a parte falhou no agir diligente e, portanto, na adoção de todas as medidas apropriadas para implementar as suas normas em seu território. (BRZEZINSKI, 2012, p. 328).

Outra obrigação substantiva destacada pela Argentina foi a do Estudo de Impacto Ambiental (EIA), o qual se fazia necessário, no caso, como mecanismo para a proteção e a preservação do meio ambiente, especialmente do aquático. Nesse sentido, convém mencionar que a decisão da CIJ em relação às fábricas de celulose no Rio Uruguai é um dos documentos internacionais mais significativos sobre o EIA. No que concerne a ele, refere-se que "é a primeira vez que um tribunal internacional considerou que uma avaliação prévia dos impactos transfronteiriços não é apenas uma obrigação baseada em tratado, mas uma exigência de Direito Internacional". Assim, em linhas gerais, ela prevê que quando uma atividade econômica possui riscos (mesmo que incertos) de impactar adversamente o meio (ainda que não de maneira irreversível), principalmente de forma transfronteiriça, faz-se essencial, antes da implementação do projeto, a produção de EIA. Inclusive, importa salientar que, no caso de empreendimentos complexos que se prolongam no tempo, pode-se exigir a realização de outros EIAs em seu decurso, os quais se relacionam a um dever de monitoramento contínuo da qualidade/proteção ambiental. Busca-se, assim, uma atuação mais do que preventiva, mas precaucional em relação ao meio ambiente. Para viabilizar esse desempenho, então, em seu conteúdo, o EIA deve apresentar o provável impacto do projeto e se ele segue um processo adequado.

Nessa senda, mesmo diante da análise detalhada dessas obrigações substanciais na decisão, entendeu a CIJ que, apesar de válidos os argumentos, a Argentina não conseguiu comprovar efetivamente a ocorrência de danos (potenciais ou concretos). Por isso, tais obrigações materiais não foram consideradas violadas por 11 votos a 3 (foram contrários os juízes Al-Khasawneh e Simma e o juiz ad hoc Vinuesa). Entre todos os votos, apesar de ter acompanhado a deliberação da Corte, o juiz Antônio Augusto Cançado Trindade elaborou importante opinião separada por não concordar com a integralidade do raciocínio que a embasou. Nela, ele defendeu que no caso deveria ter sido dada uma extensão muito maior aos princípios jurídicos (especialmente, aos de direito internacional ambiental), o que, infelizmente, não ocorreu. Passando à análise das fontes de direito internacional, destacou Cançado Trindade a autonomia dos princípios, debruçando-se, especificamente, sobre os da prevenção e da precaução (diante dos riscos e das incertezas científicas), da equidade intergeracional e do desenvolvimento sustentável. 
Diante do exposto, em suma, sobre a sentença da CIJ em relação ao caso das Papeleiras, refere-se que:

\begin{abstract}
No entanto, embora faça um discurso em prol do meio ambiente - inclusive citando trechos da decisão do caso Gabcikovo-Nagymaros - a CIJ julga de forma a tornar irrelevantes as suas próprias considerações. A tônica da sentença é a de tornar lícitos os fatos consumados (a construção e a operação da fábrica), porque "faltam provas" de que o Uruguai tenha, de fato, desrespeitado suas obrigações, que são somente de conduta ou meio, mas nunca, de resultado. (BRZEZINSKI, 2012, p. 338).
\end{abstract}

Logo, ao analisar o caso das fábricas de celulose no Rio Uruguai perante as regras e princípios do Direito Ambiental Internacional, evidencia-se que a Corte Internacional de Justiça acabou destacando pontos relevantes deles em sua decisão, como o Estudo de Impacto Ambiental (EIA), a sustentabilidade, a prevenção, entre outros. Contudo, quando da votação da violação das obrigações substantivas, a proteção ambiental não foi privilegiada. Logo, as papeleiras representam, ao mesmo tempo, um impulso na discussão de determinadas matérias do Direito Ambiental Internacional, bem como uma estagnação na aplicabilidade, no reconhecimento prático delas. A Corte, assim, deixa passar uma importante oportunidade de demonstrar à comunidade internacional sua capacidade para lidar com causas ambientais.

\title{
CONCLUSÃO
}

Pode-se traçar uma linha histórica de fatos que culminaram na formatação do Direito Ambiental Internacional (DAI) no século $\mathrm{XX}$, os quais ganharam força a partir das consequências desastrosas ao meio ambiente acarretadas pelo crescimento econômico desenfreado. As conferências internacionais sobre o meio ambiente, com destaque para a de Estocolmo (1972), tiveram um importante papel na sua consolidação, apesar de, juridicamente, suas declarações serem consideradas fontes de soft law. Entretanto, mesmo assim, seus textos são normas de direito internacional, ainda que dotadas, em sua configuração, de diferenças formais e materiais quando comparadas a outras fontes, ao núcleo duro (hard law), do direito internacional. Além do que, os conteúdos previstos nela, posteriormente, tendem a ser incorporados por tratados, decisões, entre outras fontes vinculativas do Direito Internacional, tornando-se, portanto, sem dúvidas, cogentes.

Convém mencionar que entre os casos recentes do Direito Ambiental Internacional, encontra-se a controvérsia entre Argentina e Uruguai relacionada às fábricas de celulose (2006-2010) que foi julgada pela Corte Internacional de Justiça (sendo a sua decisão uma norma de direito internacional). Contudo, como analisado no decorrer deste artigo, a aplicação 
de regras e de princípios do DAI deu-se nele de maneira inferior ao que se esperava em relação à proteção do meio ambiente. Apesar da condenação do Uruguai pelo descumprimento das obrigações processuais, não se reconheceram violações das obrigações substantivas. Assim, apesar dele ser um marco em discussões ambientais, como às referentes ao Estudo de Impacto (EIA), a Corte, em seu acórdão, deixou de avançar e contribuir mais significativamente ainda para o DAI ao priorizar a operacionalização de uma atividade econômica complexa e extremamente danosa para o meio - as papeleras.

Nesse sentido, esta pesquisa buscou detalhar o surgimento e a consolidação do DAI (com enfoque nas principais conferências de meio ambiente,) visando demonstrar princípios e regras já sedimentados em seu conteúdo, bem como sua (in)aplicabilidade perante um caso concreto: das papeleiras no Rio Uruguai.

\section{REFERÊNCIAS BIBLIOGRÁFICAS}

BIRNIE, Patricia; BOYLE, Alan. International Law \& Environment. Oxford University Press, 2002.

BOYLE, Alan. Developments in International Law of EIA and their Relation to the Espoo Convention. Disponível em:

<http://www.unece.org/fileadmin/DAM/env/eia/documents/mop5/Seminar_Boyle.pdf $>$. Acesso em: 10 jun. 2015.

BRZEZINSKI, Maria Lúcia Navarro Lins. Direito internacional da água doce: fontes, regimes jurídicos e efetividade. Curitiba: Juruá, 2012.

CARSON, Rachel. Primavera Silenciosa. 2. ed. São Paulo: Edições Melhoramentos, 1969.

CNUDS. O futuro que queremos. 2012. Disponível em:

<http://www.uncsd2012.org/thefuturewewant.html>. Acesso em: 23 mar. 2015.

CNUMAD. Nosso Futuro Comum. 1987. Disponível em:

<http://www.undocuments.net/wced-ocf.htm>. Acesso em: 21 mar. 2015.

CONFERÊNCIA DAS NAÇÕES UNIDAS SOBRE DESENVOLVIMENTO

SUSTENTÁVEL. O Futuro que queremos. 2012. Disponível em:

〈http://www.mma.gov.br/port/conama/processos/61AA3835/O-Futuro-que-queremos1.pdf $>$.

Acesso em: 18 mar. 2015.

CORTE InTERnaCiOnAL DE JUSTIÇA (CIJ). Pulp Mills on the River Uruguay

(Argentina v. Uruguay). 2010. Disponível em: <

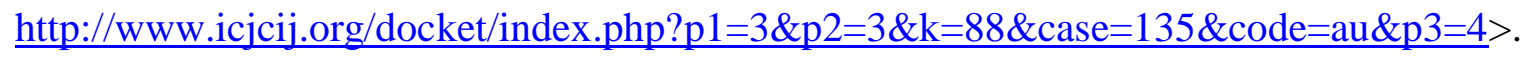

Acesso em: 12 jun. 2015. 
DERANI, Cristiane. Direito ambiental internacional e globalização. In: RAMINA, Larissa; FRIEDRICH, Tatyana Scheila (Orgs.). Direito internacional multifacetado: direitos humanos, meio ambiente e segurança. Curitiba: Juruá, 2014, v. II, p. 13-33.

DERANI, Cristiane. Direito ambiental econômico. São Paulo: MaxLimonad, 1997.

INSTITUTO BRASILEIRO DE DEFESA DA NATUREZA. Rio+20: não traiam seus compromissos sobre o direito humano à água e ao saneamento. 2012. Disponível em: <http://www.ibdn.org.br/novo/index.php/ultimasnoticias/1292-rio20-nao-traiamseuscompromissos-sobre-o-direito-humano-a-agua-e-ao-saneamentoa.html>. Acesso em: 18 mar. 2015.

MCCORMICK, J.. Rumo ao paraíso: a história do movimento ambientalista. Rio de Janeiro: Relume Dumará, 1992.

MEADOWS, Donela and Denis. Limits to growth - the 30 year update. Earthscan, London, 2006.

ONU. Rio + 20. Disponível em: 〈http://www.onu.org.br/rio20/temas-agua/〉. Acesso em: 20 mar. 2015.

Declaração da Conferência das Nações Unidas sobre o Meio Ambiente Humano. 1972. Disponível em:

<http://www.apambiente.pt/_zdata/Politicas/DesenvolvimentoSustentavel/1972_Declaracao Estocolmo.pdf >. Acesso em: 19 mar. 2015.

Declaração do Rio sobre Meio Ambiente e Desenvolvimento. 1992. Disponível em: <http://www.mma.gov.br/port/sdi/ea/documentos/convs/decl_rio92.pdf >. Acesso em: 19 mar. 2015.

PNUD. Secretário-geral da ONU lança relatório sobre os Objetivos de Desenvolvimento Sustentável e sobre os desafios a serem enfrentados até 2030. 2015. Disponível em: <http://www.pnud.org.br/Noticia.aspx?id=4009>. Acesso em: 25 mar. 2015.

PNUMA. Da Rio92 à Rio+20. 2011. Disponível em:

<http://www.onu.org.br/rio20/img/2012/01/Keeping-Track-of-Changing-

EnvironmentUNEP.pdf $>$. Acesso em: 20 out. 2014.

SACHS, Ignacy. Desenvolvimento: includente, sustentável, sustentado. Rio de Janeiro: Garamond, 2008.

SCHWABACH, Aaron. International Environmental Disputes. Abc Clio, Santa Barbara, 2006.

SOARES, Guido Fernando da Silva. Direito Internacional do Meio Ambiente. Ed. Atlas, São Paulo, 2003. 
THIELBÖRGER, Pierre. The right(s) to water: the multi-level governance of a unique human right. Bochum: Springer, 2014.

VILLAR, Pilar Carolina. Governança hídrica: definições e arcabouço legal. 2015. Disponível em: <https://www.aguaegestao.com.br/es/node/671>. Acesso em: 20 mar. 2015.

WINTER, Gerd. Esenvolvimento sustentável, OGM e responsabilidade civil na União

Europeia. São Paulo: Millennium Editora, 2009. 